\title{
Child Resistant Metal Container Closure
}

National Cancer Institute

\section{Source}

National Cancer Institute. Child Resistant Metal Container Closure. NCI Thesaurus. Code C96113.

Metal closure that is designed or constructed to be significantly difficult for children under five years of age to open and not difficult for normal adults to use properly. 